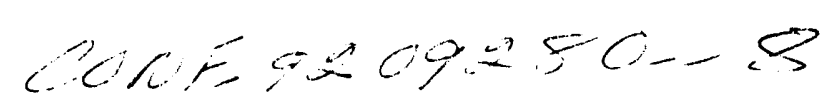

BNL- -48322

DE93 006646

$$
\text { FEBU - }
$$

\title{
A COMPARISON OF THE DOSE - RBE AND THE BIOLOGICAL DOSIMETRY APPROACHES FOR TREATMENT PLANNING IN BNCT
}

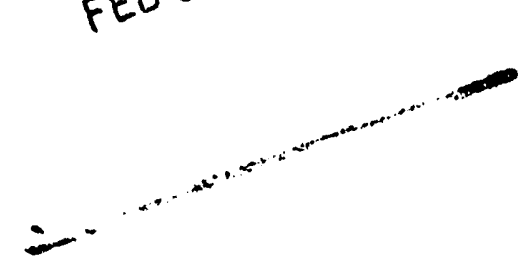

\author{
B.H. Laster ${ }^{1,2}$, H.B. Liu', C.R. Gordon', and V.P. Bond \\ 'Medical Department, Brookhaven National Laboratory, \\ Upton, NY 11973 \\ 2 Department of Radiation Oncology, University Hospital \\ Stony Brook, NY 11794
}

Treatment planning for clinical trials with boron neutron capture therapy (BNCT) is complicated substantially by the fact that the radiation field generated by the activating external neutron beam is composed of several different types of radiation, i.e., fast neutrons, recoil protons from elastic collisions with hydrogen, gamma rays from the reactor and from neutron capture by body hydrogen, protons from nitrogen capture, and the products of the NCT interaction. Furthermore, the relative contribution of each type of radiation varies with depth in tissue. Because each of these radiations has its own RBE, and the RBE of the fast neutron component will not be constant as the neutron spectrum changes with depth, the problem of predicting the severity of the biological effect, in depth, becomes complex indeed.

In order to attack this problem, Monte Carlo calculations of dose, checked against benchmark measurements, are employed. Two approaches are then used to assess the severity of the effect. In the first, the effective dose $\left(D_{E x}\right)$ is determined by summing the products of $(D \cdot R B E)$ for each radiation. The other approach, "biological dosimetry", involves placing cells at the location for which the $D_{\mathrm{EF}}$ was calculated. Using a dose-response curve from a low-LET radiation, e.g. ${ }^{137} \mathrm{Cs}$ gamma rays $\left(\mathrm{D}_{\mathrm{r}, \mathrm{c}}\right)$, the "photon equivalent dose" (PED, or $\left.\mathrm{D}_{\mathrm{p}}\right)$ can be determined. If the $R B E$ values used are correct, the $D_{E F}$ and the $D_{p}$ should be essentially identical.

In our prelimirary experiments, the agreement was not satisfactory. The object of this paper is to describe these initial efforts in some detail, and then outline our plans for attempting to reconcile the differences. Because we regard Monte Carlo as an essential part of treatment planning, it is imperative that this complex problem be resolved.

The first step was to establish an apparent RBE (RBEa) for fast neutrons in the epithermal beam of the Brookhaven Medical Research Reactor (BMRR). Cells were irradiated, in air, at the epithermal beam of the BMRR in a configuration and geometry that yielded $\sim 4 \%$ thermal neutrons. Thus, the major dose components were fast neutrons, gamma rays and protons from the $n, p$ reaction with nitrogen. An RBE of 1 was used for gamma, and an RBE, of 2 for the protons, a value that has been estimated (1), and measured (2)'. For the BMRR experiments, survival was first plotted as a

(Research supported by U.S. DOE contract DE-AC02-76CH00016)

DISTRIBUTION OF THIS DOCUMENT IS UNLIMTTED

'The term RBE, is applied here since the measurements in (2) were carried out in a mixed-field. 
Table I. Physical doses for BMRR phantom experiment (all doses given in Gy)

\begin{tabular}{|c|c|c|c|c|c|}
\hline Position & $D_{*}$ & $D_{i, \text { pip }}$ & $D_{\gamma}$ & $D_{\text {boroes }}$ & $D_{\text {lat }}$ \\
\hline 1 & 0.522 & 0.720 & 2.349 & - & 3.591 \\
\hline$\% D_{b \alpha}$ & 14.5 & 20.0 & 65.4 & - & -100 \\
\hline 2 & 0.621 & 0.414 & 3.114 & $\cdots$ & 4.149 \\
\hline$\% D_{v a t}$ & 14.9 & 9.9 & 75.0 & - & $\sim 100$ \\
\hline 3 & 0.450 & 0.243 & 2.880 & - & 3.573 \\
\hline$\% D_{10 a}$ & 12.6 & 6.8 & 80.6 & - & -100 \\
\hline 4 & 0.270 & 0.135 & 2.115 & - & 2.520 \\
\hline \%o $D_{10 x}$ & 10.7 & 5.4 & 83.9 & - & $\sim 100$ \\
\hline $1^{*}$ & 0.174 & 0.264 & 0.783 & 2.178 & 3.399 \\
\hline $\mathscr{H} D_{\text {rat }}$ & 5.1 & 7.8 & 23.0 & 64.1 & $\sim 100$ \\
\hline $2 *$ & 0.207 & 0.138 & 1.038 & 2.496 & 3.879 \\
\hline \% $D_{\text {lat }}$ & 5.3 & 3.6 & 26.8 & 64.3 & $\sim 100$ \\
\hline $3^{*}$ & 0.150 & 0.081 & 0.960 & 1.809 & 3.000 \\
\hline$\% D_{\text {lot }}$ & 5.0 & 2.7 & 32.0 & 60.3 & $\sim 100$ \\
\hline $4^{*}$ & 0.090 & 0.045 & 0.705 & 1.074 & 1.914 \\
\hline$\% D_{l a t}$ & 4.7 & 2.4 & 36.8 & 56.1 & $\sim 100$ \\
\hline
\end{tabular}

* with $30 \mu \mathrm{g} / \mathrm{g}$ enriched boric acid

function of MW minutes. This was subsequently converted to dose (D) by means of Monte Carlo calculations, which yielded a conversion factor of Gy/MW min (3). Cell survival curves for the BMRR and ${ }^{137} \mathrm{Cs}$ gamma rays are shown in Figs. 1 and 2. Note the absence of effect from boric acid with the ${ }^{137} \mathrm{Cs}$ gamma rays. Irradiation techniques and cell culture assay methods are detailed elsewhere $(4,5)$. The $10 \%$ level of survival was selected for the determination of both $D_{E F}$ and $D_{p}$. Assuming that the RBE, of 2 for the $0.6 \mathrm{MeV}$ protons from nitrogen capture is correct, the $R B E$, for the fast neutrons was determined by means of the following equation:

$$
D_{E F}=D_{\text {pox }} \cdot R B E_{a}+D_{\gamma} \cdot R B E+D_{\text {max }} \cdot R B E_{a}
$$

Substituting the $D_{p}$ for the $D_{E F}$, and using the RBE's above, the RBE, for fast neutrons was calculated to be 3.6.

We then placed cells at depth $(1.4,3.6,5.8$, and $8 \mathrm{~cm})$ in a lucite phantom, and the RBE for neutrons was again determined. The arrows in Fig. 3 show the sequential positions of the cell holders for these irradiations (position 1 is nearest the beam). Physical doses are given in Table I. The RBE, for fast neutrons at position 1, calculated by substituting $D_{p}$ for the $D_{E F}$ in equation 1 , was found to be 4.8. Thus, in order to make $D_{\mathrm{EF}}$ equal to $D_{p}$, it was necessary to adjust the RBE for fast neutrons upward, from 3.6 to 4.8 . equation was used:

To determine an RBE, for the boron reaction products, the following

$$
R B E_{a b \text { boros }}=D_{p} / D_{\text {borou }}
$$

When $30 \mu g^{10} \mathrm{~B} / \mathrm{g}$ boric acid was used, the RBE, was calculated to be 3.6, closely approximating that reported earlier (6). As shown in Table II, the $D_{E F}$ is equal to the $D_{B}$ in the first two cell 
Table II. RBE, for neutron and boron doses

\begin{tabular}{cccccc}
\hline Position & $\begin{array}{c}\text { Physical } \\
\text { dose (Gy) } \\
\text { BMRR }\end{array}$ & $\begin{array}{c}\text { Per cent } \\
\text { survival }\end{array}$ & $\begin{array}{c}\text { Absorbed } \\
\text { dose (Gy) } \\
{ }^{37} \mathrm{Cs}\end{array}$ & $\begin{array}{c}\text { RBE, } \\
\text { neutrons } \\
\text { (fast) }\end{array}$ & $\begin{array}{c}\text { RBE } \\
\text { Boron-10 } \\
(30 \mu \mathrm{g} / \mathrm{g})\end{array}$ \\
\hline 1 & 3.6 & 9.6 & 7.2 & 4.8 & - \\
2 & 4.1 & 17.6 & 6.2 & 4.8 & - \\
3 & 3.6 & 12.3 & 6.7 & $11.9(?)$ & - \\
4 & 2.5 & 29.8 & 4.2 & $11.4(?)$ & - \\
$1^{*}$ & 3.4 & 2.4 & 10.3 & 4.8 & 3.6 \\
$2^{*}$ & 3.9 & 2.2 & 10.2 & 4.8 & 3.6 \\
$3^{*}$ & 3.6 & 2.6 & 10.3 & $31.0(?)$ & 3.6 \\
$4^{*}$ & 1.9 & 13.5 & 6.5 & $38.9(?)$ & 3.6 \\
\hline
\end{tabular}

RBE nitrogen, assumed 2

RBE gamma, assumed 1

with $30 \mu g^{10} \mathrm{~B} / \mathrm{g}$ boric acid

positions only $\left(1,1^{*}, 2,2^{*}\right)$. For positions 3 and 4, major adjustments in the apparent RBE's were required in order to make $D_{\mathrm{EF}}$ equal to $D_{\mathrm{p}}$.

Several factors may be influencing the apparent effectiveness of the various radiations at depth in the phantom. The gamma dose, relative to the fast neutron dose, increases with depth (Table I). Also, the energy spectrum of the fast neutrons changes with depth, which should increase the RBE. The high and low LET radiations may act synergistically (7), and the RBE of 2 , assumed for recoil protons, may not be correct. Because the absolute value for the dose of neutrons decreases rapidly with depth, the calculated neutron dose may be imprecise. The neutron dose in depth is low, so it may result in using a large number to adjust the dose. 
Figure 3

It is evident that the use of Monte Carlo calculations and assumed RBE's did not provide an accurate assessment of the effective dose in our experiments designed to simulate patient treatment planning for BNCT. The difficulties attendant upon the approach include, a) the accuracy of the RBE values for all components are in question because they can not be determined separately, and b) additional mechanisms involved in the interactions may change the severity of effect ( e.g. synergism).

It is our contention that a cell system which is highly reproducible with respect to its response to photon irradiation should be used as a bench mark measurement of the PED, and thus of the true $D_{E F}$ for BNCT radiations. We intend to pursue these studies further by positioning cells at given regions of interest in a phantom that is tissue equivalent for neutrons. Their response will be evaluated with and without boron, under conditions of homogeneous and heterogeneous intracellular boron distribution. It is anticipated that the difficulties outined above can be resolved so that the approach using calculations, measurements, $R B E$ and $D_{E F}$ can provide a realistic and precise prediction of the severity of biological effect at any pre-determined site.

\section{REFERENCES}

1. R.G. Zamenhof, B.W. Murray, G.L. Brownell, G.R. Wellum and E.I. Tolpin, Boron neutron capture therapy for the treatment of cerebral gliomas.I:Theoretical evaluation of the efficacy of various neutron beams. Med. Phys. 2:47-60 (1975).

2. D. Gabel, R.G. Fairchild, B. Larsson and H.G. Bormer, The relative biological effectiveness in V79 Chinese hamster cells of the neutron capture reactions in boron and nitrogen. Radiat. Res. 98:307-316 (1984).

3. H.B. Liu and R.M. Brugger, Dose calculation and treatment planning for the Brookhaven NCT facility, in: Proceedings of the Fifth International Symposium on Neutron Capture Therapy. Plenum Press (1993).

4. B.H. Laster, S.B. Kahl, E.A. Popenoe, D.W. Pates and R.G. Fairchild, Biological efficacy of low-density lipoprotein for boron neutron capture therapy as measured in cell culture. Cancer Res. 51:4588-4593 (1991).

5. R.G. Fairchild, S.B. Kahl, B.H. Laster, J.Kalef-Ezra and E.A. Popenoe, In vitro determination of uptake, retention, distribution, biological efficacy, and toxicity of boronated compounds for neutron capture therapy:A comparison of porphyrins with sulfhydryl boron hydrides. Cancer Res. 50:4860-4865 (1990).

6. M.A. Davis, J.B. Little, K.M.M.S. Ayyangar and A.R. Reddy, Relative biological effectiveness of the ${ }^{10} \mathrm{~B}(\mathrm{n}, \alpha)^{7} \mathrm{Li}$ reaction in HeLa cells. Radiat. Res. 43:534-553 (1970).

7. M. Zaider and H.H. Rossi, The synergistic effects of different radiations, Radiat. Res. 83:732739 (1980).

\section{DISCLAIMER}

\footnotetext{
This report was prepared as an account of work sponsored by an agency of the United States Government. Neither the United States Government nor any agency thereof, nor any of their employees, makes any warranty, express or implied, or assumes any legal liability or responsibility for the accuracy, completeness, or usefulness of any information, apparatus, product, or process disclosed, or represents that its use would not infringe privately owned rights. Reference herein to any specific commercial product, process, or service by trade name, trademark, manufacturer, or otherwise does not necessarily constitute or imply its endorsement, recommendation, or favoring by the United States Government or any agency thereof. The views and opinions of authors expressed herein do not necessarily state or reflect those of the United States Government or any agency thereof.
} 


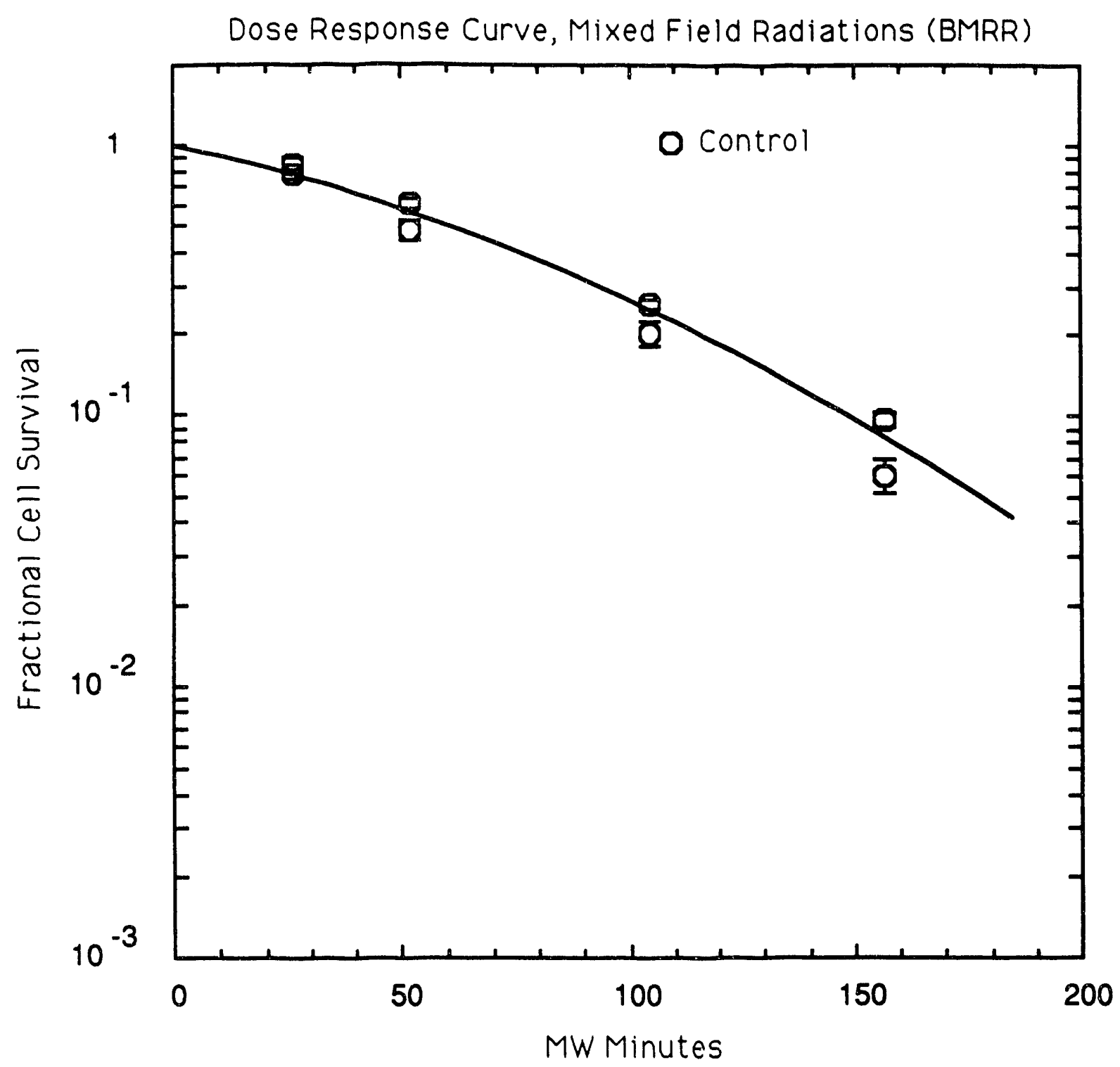




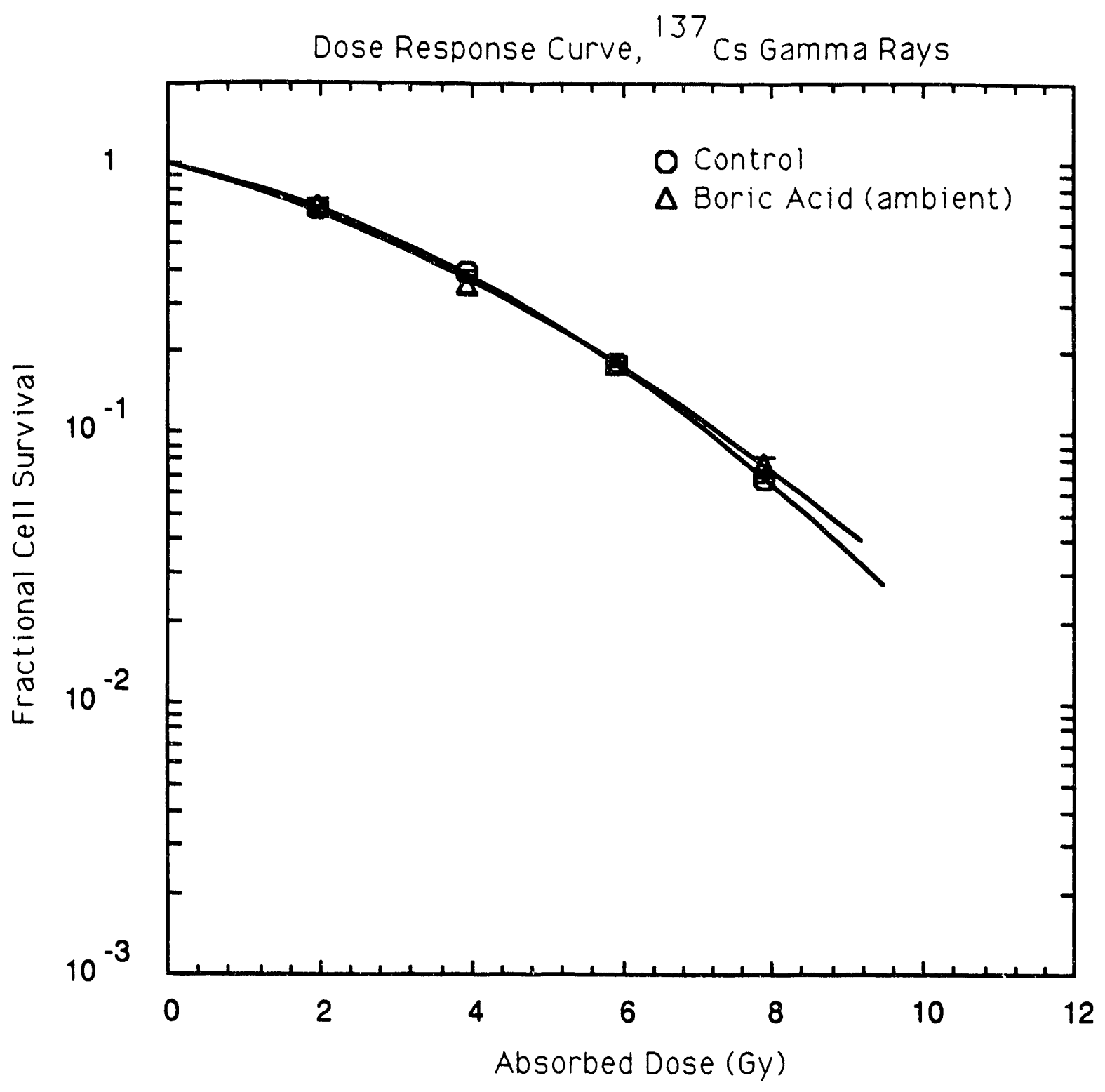




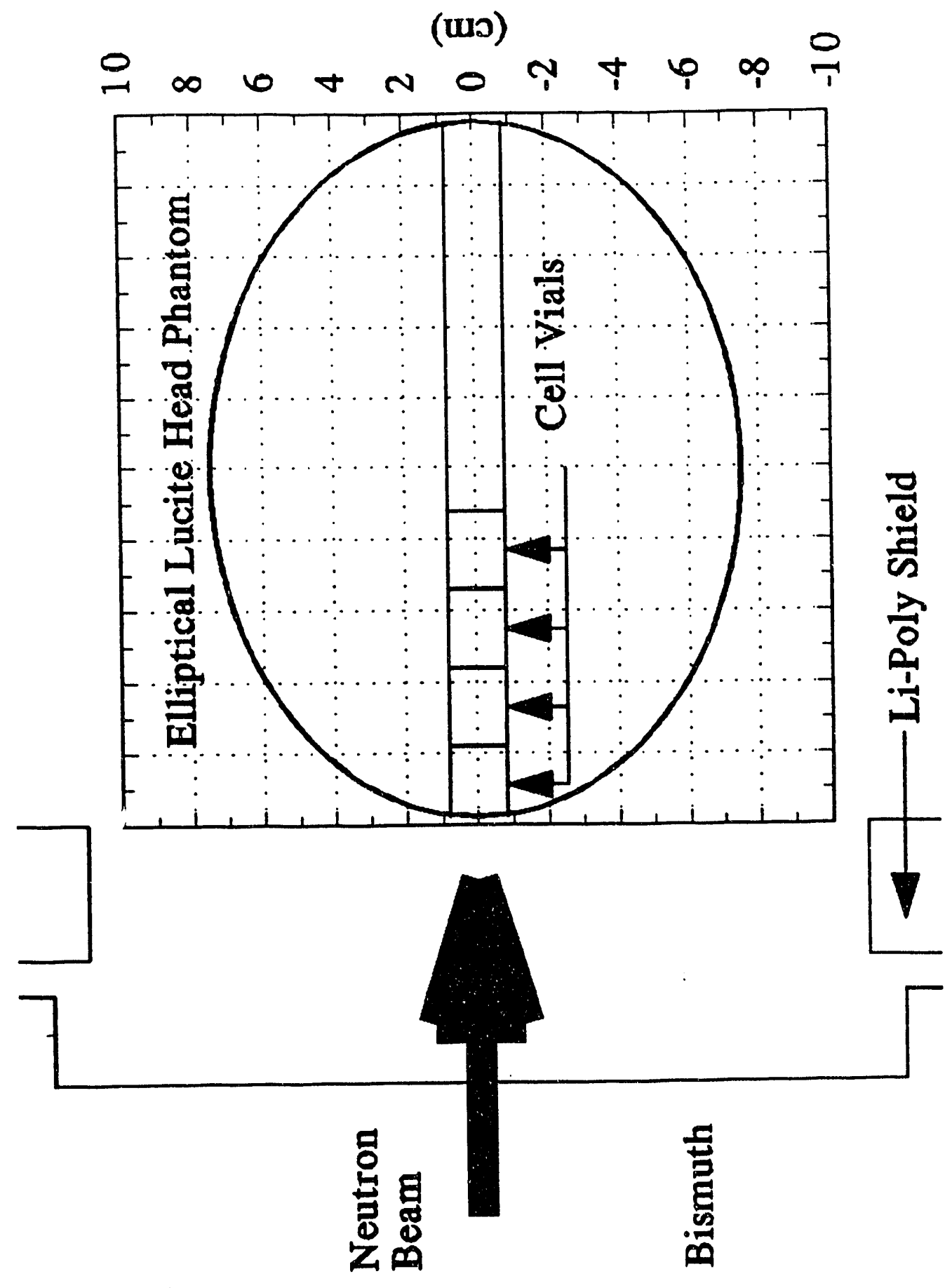



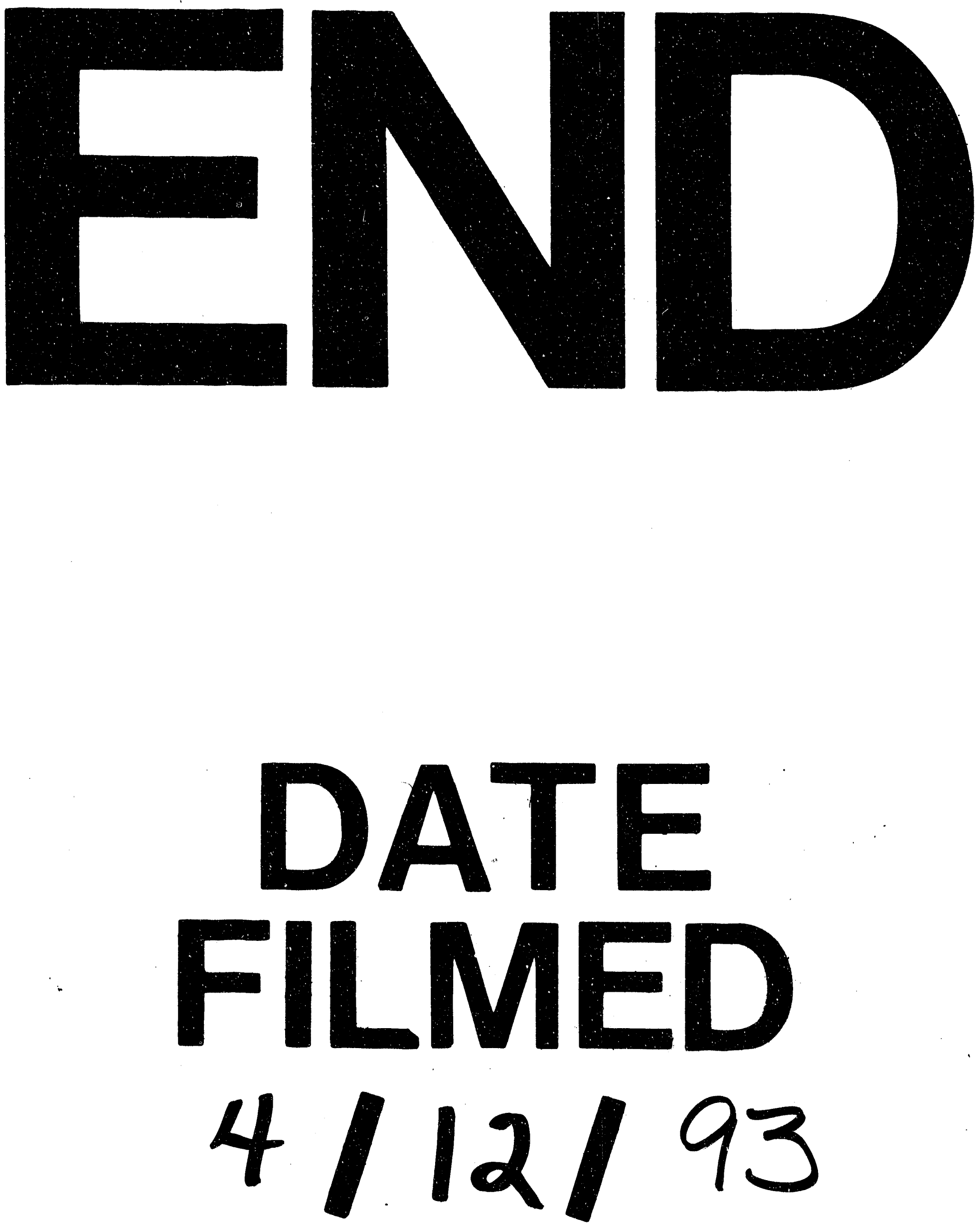
